\title{
Tobias Nanz
}

\section{The Red Telephone}

\author{
A Hybrid Object of the Cold War
}

\section{1}

One wrong word, a moment of inattention or a technical malfunction could have unthinkable consequences. At stake is nothing less than the complete devastation of the Soviet Union and the United States. The interpreter-translator and first-person narrator of the short story "Abraham '59 - A Nuclear Fantasy" (Aiken 1959: 18-24) is sitting with the American President in a room in the basement of the White House and has just been informed of a dramatic situation. A bomber squadron of the US Air Force has not returned from a routine flight and now beyond the reach of American fighter-interceptors -, acting on its own authority, has announced a nuclear attack on Moscow in order to force the US leadership to go to war against the Soviet Union. But the President has no intention of giving in to the extortion. He wants to contact Nikita Khrushchev "via transatlantic telephone" (Aiken 1959: 23) and, if the Soviet defense cannot stop the attack, offer New York as a compensatory sacrifice, in accordance with the biblical formula, "an eye for an eye, a tooth for a tooth.” The American ambassador in Moscow and the Soviet ambassador to the UN in New York have now been brought into a conference call on the red telephone. According to the plan, if the connection to Moscow is severed by the detonation of the atomic bombs, the President would then order the bombing of New York, which in turn could be verified by the disruption of the telephone connection. The destruction of their own city would provide credible proof that the US attack on Moscow was an accident, instigated by pilots who are clearly mentally disturbed, from whom one would have in fact expected "fanatic devotion to their superiors" (Aiken 1959: 20).

The situation facing the American Commander-in-Chief can be described using ideas from game-theory dating from that period, which were further developed by specific think tanks in order to be applied to crisis situations in the Cold War. The narrator of the short story refers in his recollections to the "new-model theorists of Cold War" (Aiken 1959: 18), who had developed a series of formulas

Originally published in German (Nanz 2014) and translated into English by Gregory Sims.

https://doi.org/10.1515/9783110580082-015 
which could be used to determine the outcome of possible military conflicts. The possible moves which the President considers and presents to his interpreter concern the steps to be taken after the bombing of Moscow: were the American Government not to respond at all, then a comprehensive Soviet retaliation would be likely. Alternatively, out of necessity, the American military could provide flanking support for the rogue bomber squadron and undertake an all-out attack, deploying all forces. How would the Soviet leadership react? Since, in the case of a US first strike, they would have sufficient potential for a counterattack, there would be a strong likelihood that the Soviet leadership could order and carry out a comprehensive retaliation. "As near as we can figure it," says the President, concluding his first thoughts on the matter, "the odds are not favorable in either case" (Aiken 1959: 22). In both cases, the obliteration of the United States would be possible and the fate of the country would hang in the balance.

The President's strategy is to carry out a unilateral and unconditional move (Dixit and Nalebuff 1991: 119-141): through his declaration to order the destruction of New York should Moscow be bombed, he seeks to restore credibility and to prevent a concurrent move or a counter-strike by the Soviet military. A prerequisite for this is, on the one hand, the cooperation between the two leaders, which in the short story takes the form of the announced negotiations via telephone. The telephone also constitutes the basis of the trust that needs to be restored, since the destruction of New York can be transmitted in real time thanks to the transatlantic telephone connection. On the other hand, the destruction of New York must not be seen as an aggressive act on the part of the Soviet Union, since otherwise the strategy of tit-for-tat could lead to a spiral of violence in which the American President would see himself forced to carry out a retaliatory attack, which in turn would provoke the Soviet side to launch a further attack. This series of strikes and counter-strikes, of "an eye for an eye, a tooth for a tooth" - precisely, tit-for-tat - , could be pursued indefinitely, ultimately leading to the complete destruction of both countries. By deciding in favor of the obliteration of New York, the President opts for an unconditional move, which leaves no room for misunderstanding and establishes credibility. ${ }^{1}$

The American President now plans to telephone his Soviet colleague to explain the situation to him, to explain his intentions and the strategy for preventing a nuclear war. Hence the warning to the interpreter: there can be no translation errors and he must choose his words precisely.

1 On the following reflections from game theory see Dixit and Nalebuff (Dixit and Nalebuff 1991: 109-113, 119-141). 
In “Abraham '59," three factors are mentioned that appear important for coping with a crisis and averting a disaster on an unprecedented scale during the Cold War. First, in a situation such as this where time is a critical factor - the bombers need four hours to reach Moscow - the medium and technology of the telephone is an indispensable prerequisite to being able to negotiate a strategy at all. The classic diplomatic path during the Cold War, which would have involved an exchange of letters and telegrams between the Embassies in the respective capitals (Berridge 2005: 97), is clearly too time-consuming as a response to the crisis.

Secondly, the American President is depicted as an actor who exhibits his authority and his composure through strategic thinking. The reader of the short story is not privy to his negotiations with the Soviet side; rather, one witnesses solely the strategic considerations derived from game theory that guide the dialogue. The telephone with the direct line to Moscow is rather peripheral in the story, since the focus is plainly on the deliberations and the way they unfold. What is being deployed here is the "old figure of the master political leader," as Jacques Derrida once remarked, a figure that has a rather secondary "relationship with the machine." The relationship with technical media is mediated by the "secretary-slave" who is able to observe the master "absorbed in thought" (Derrida 2005: 29-30). The President, who has consulted his advisors, is established in the literary text as an authority figure, independently able to weigh up the pros and cons of a decision and think it through to the end. A "power of symbolization" (Legendre 2001: 41) is constructed that validates the elements and filiations of society, and ultimately conveys the impression that, in a crisis situation, the institutions do indeed function and the best possible decisions are made, even though these decisions may have disastrous consequences, as in "Abraham '59." Here literature is contributing to the construction of the political imaginary in a crisis situation.

Thirdly, the story demonstrates the dependence of the President not only on a technical medium, but also on an human actor. The role of the interpreter is not restricted to that of a figure on whom the President tries out his strategy; the interpreter is also the third party without whom the negotiations could not come about at all. ${ }^{2}$ That the American head of state exhorts the interpreter to choose his words as precisely as possible not only indicates how tense the situation is, but also points to the threatened loss of the President's authority due to his linguistic incompetence. This may be what the "dialectic of human power" consists in: from the moment a holder of power consults an advisor or requires

2 See Serres on the function of the third (Serres 1982). 
an interpreter, his direct exercise of power is "subjected to indirect influences" (Schmitt 2008: 21). The President's discourse is situated in the midst of a larger discourse on authority that examines the roles, as well as the legitimacy, of the speakers, since the interpreter is not subject to democratic election.

All these deliberations and questions have a common centre that is introduced rather indirectly in the story and then barely mentioned further; namely the "transatlantic telephone" with the "extension phone" for the interpreter, which in the course of the discussions is integrated into a larger telephone network. In the transatlantic telephone several discourses are bundled together that are able to shed light on crisis management strategies during the Cold War and provide us with knowledge concerning the fear of a possible nuclear war - discourses in which fiction and facts intermingle. In "Abraham '59" what is beginning to take shape is what would later become famous as the 'red telephone,' an object in which a number of epistemological questions come together: how is the political imaginary generated in times of crisis and what role is assigned to human and non-human actors in this process?

\section{2}

The nuclear fantasy in question was published in Dissent Magazine, a periodical that adopted a critical position on McCarthyism in America in the 1950s. The supposed author, a certain F.B. Aiken, is described as an "industrial consultant and one of the founders of control system analysis" (N.N. 1959: 24). Thus, one might view the story as input from an expert who, in the context of fiction, is taking a position on what could happen if, due to a psychological disturbance, automated processes involving non-human and human actors within the military deterrence and defense system do not function according to plan. In all likelihood, the author was also not unfamiliar with issues related to speech/orality and writing: if "F.B. Aiken" is pronounced in different ways in English, it can sound like F. Bacon, that is, like Francis Bacon. This différance points to the actual author of the story, the American professor of political science Harvey Wheeler (Ruddick 2012: 164), who was a great proponent of the early modern English philosopher and politician, considered to be the precursor of empiricism. Wheeler's word play can also be read as a commentary on Ferdinand de Saussure's reflections on articulated sounds being closer to the "truth" (Saussure 2011), and places the President in a phonocentric and logocentric light (Derrida 1976: 10 -12), where the voice carries more weight in negotiations and is supposedly closer to thought processes and the truth. 
At the same time, however, a deconstructive pointe is seemingly being made: the precision in simultaneous interpreting, which the President in Wheeler's story is calling for, proves to be a difficult undertaking. Is it really that easy to assign clear meaning(s) amidst all the signal-noise of interpreting and the telephone line? Would not a written message be a much more precise form of communication? Along with the book Red Alert by Peter George, published in 1958, the story “Abraham '59," written in 1956 (Ruddick 2012: 163), is one of the earliest texts in which the 'red telephone' makes its appearance as a dispositif (Foucault 2001a: 298-304) [an apparatus] and object of knowledge.

The red telephone is an object that since the 1950s and 1960s has become known to an ever-larger public in the United States and Western Europe. The model for it is doubtless the radio-telephone link between Washington and London that was set up under the strictest secrecy during the Second World War and first used in 1943. A sophisticated encryption system meant that, for the first time, these transatlantic radio-telephone calls could not be intercepted (Hodges 2012: 247-248). Rooms full of technology and countless phonograph records, which had to be synchronized for encoding and decoding at both ends, were shipped from America to Britain. President Franklin D. Roosevelt and Prime Minister Winston Churchill made extensive use of this voice communication to coordinate military operations and to cultivate the alliance. The 'red telephone,' which began to take shape during the Cold War, has a further peculiarity: it is not merely a material object that can be used for telephone calls in the event of a crisis, it is rather a hybrid object (Latour 1993: 10) in which materiality and factuality are intermingled with stories and fictions.

It is a (technical)-communicational apparatus (dispositif) that facilitates an analysis of the theatrical strategies the decision-makers devise to carry out their actions. At the same time, it facilitates an examination of technical aspects such as the susceptibility to disruption of the transmission lines and the technical apparatuses, as well as the question of the distinction between a message and signal-noise. It is part of an actor-network in which fictional stories about possible crises are as significant as the 'hotline' itself, which was set up as a teletype connection in Washington and Moscow after the Cuban missile crisis. While the 'red telephone' never actually existed in reality, it nonetheless circulated as fiction in the cultural, social, and political discourses of the Cold War, as is testified to by films and books, anxieties and fears, and the ways that political actions are staged.

In other words it can be said that, when it first appeared, the 'red telephone' was somewhat amorphous and rather insignificant. For the constitution of the notorious Cold War apparatus, an increase in the production of signs was required, along with an increase in symbolic attributions, narrative strategies, 
and rhetorical figures. In turn, as a discursive object, the 'red telephone' can provide us with specific knowledge about its time. Any knowledge or order of knowledge privileges and produces specific forms of representation (Vogl 1999: 13) that can take on material form in an object such as the 'red telephone.' It is traversed by and formed out of discourses and was a non-human actor in fictional crises, while the operations of the actual teletype connections mostly faded into obscurity in real crises. The 'red telephone' provides us with answers to questions concerning the role assigned to technical media in a crisis situation, and how politicians want to be portrayed in office.

\section{3}

Three years after the release of "Abraham '59" - and coinciding with the Cuban missile crisis - Harvey Wheeler, together with the political scientist Eugene Burdick, published the novel Fail-Safe. The affinity between the two texts is unmistakable: in Fail-Safe a malfunction in the system also triggers a US attack on the Soviet Union, again unsought by the political or military leadership. The President is unable to stop the bombers and therefore contacts Khrushchev by telephone. This time, however, the disorder is not psychological, but technical: the attack is not caused by a deranged flight crew, but rather by a technical defect at the Strategic Air Command in Omaha. In both texts, nuclear war is prevented in accordance with the Old Testament principle of "an eye for an eye, a tooth for a tooth." The "conference line” (Burdick and Wheeler 1999: 189, 213, 257, 275) between the two state leaders is supplemented by dedicated lines to the ambassadors in New York and Moscow; when the "shriek of the melting telephone" (Burdick and Wheeler 1999: 262) indicates the atomic destruction of the Soviet capital, an aircraft of the US Air Force bombs New York as a selfimposed retaliatory strike, and the obliteration of the city is verified by a further telephonic "shriek." In the short story, Abraham's sacrifice is presented as a thought-experiment on the part of the President prior to the activation of the 'red telephone'; in Fail-Safe it becomes a proposal that is finally enacted through the destruction of both cities.

In several chapters of Fail-Safe the "conference line" occupies center stage, as the two leaders seek to de-escalate the crisis. In the novel, the term "red telephone" or "red phone" (Burdick and Wheeler 1999: 56, 129, 187) is reserved for the apparatuses that, in urgent cases, provide the connection between the President's bunker and Strategic Air Command in Omaha or the Pentagon, whereas the dedicated line to Moscow is not yet assigned any specific color, with the designations "conference line" and "hot wire" (Burdick and Wheeler 1999: 129) 
highlighting its mediating function. Buck, the President's interpreter, provides the translations via an extension telephone while the Soviet interpreter remains in the background. After providing his translations, Buck occasionally senses "a long moment of tension," which might be an expression of the "wills of two men," whose "strength poured through the line" (Burdick and Wheeler 1999: 190). The pauses in the dialogue and the resulting strained silence are agonizing - "it was physically unpleasant" (Burdick and Wheeler 1999: 194) - and experienced as a "test of will” (Burdick and Wheeler 1999: 193), but the pauses also take on a strategic value when Buck can listen in to the background discussions in the Soviet operations center: "Buck could pick up only a few of the words. He quickly wrote a sentence on a pad and turned it to the President. It said, 'Someone is trying to persuade him that it is a trick, arguing for "strike-back in full power' or something close to that'” (Burdick and Wheeler 1999: 195).

At one point the President deliberately speaks too quietly, in order to play for time by using Buck's request for him to repeat what he said and to allow Khrushchev's temper to cool off (Burdick and Wheeler 1999: 196); at a further point in the exchange, Buck gives the President a sign that Khrushchev feels cornered and indicates that the President is not allowed to ask any more questions "From a long distance came the single word, "No. [...] Khrushchev had given everything” (Burdick and Wheeler 1999: 221). Or alternatively, just the right translation has to be found, one that will have a de-escalating effect - how should one formulate in Russian the President's question "Why did you not launch an offensive?” As Buck realizes, “offensive” can have multiple meanings in Russian, for example, "masculinity" and "potency" as well as "challenge." He opts for a reformulation of the question: "Why did you not defend yourself by counterattacking?” (Burdick and Wheeler 1999: 215), thus providing a translation that has a de-escalating effect in the chain of signifiers. Khrushchev's voice reveals his determination, which Buck registers in the President's notebook with the words "Finality. Tone heavy, final. K. has decided," or even "rage" (Burdick and Wheeler 1999: 260). Finally, after the President has put forward his proposal to sacrifice New York, both sides fall into silence: "Then there was a deep silence. Suddenly, like a mechanical mockery, there was a flare-up of static on the line. It sounded like some macabre laugh, something torn from the soul of the mechanical system" (Burdick and Wheeler 1999: 262). The flare-up of static from the vaporized telephone, which indicates the destruction of Moscow, has "an animal-like quality [...]. The screech rose sharply, lasted perhaps five seconds, and then was followed by an abrupt silence" (Burdick and Wheeler 1999: 279).

The 'red telephone' is constituted in the course of a serious crisis and opens up an arena in which the technical aspects such as telephone lines, extensions, 
microphones, or static interference and other forms of signal noise come together with human actors, and dramatic storylines ensue. The drama is characterized in particular by the fact that the 'red telephone' reverses a classic feature of media theory. As Marshall McLuhan observed, media are fundamentally characterized by the fact that they disguise their operations, become imperceptible, and draw attention to themselves and their own agency only when they malfunction (McLuhan 2001; Vogl 2007). With the 'red telephone,' however, disruption seems to be the standard case: breaks in conversational exchanges that seem infinitely long, telephone lines that transmit not just signal noise but apparently also the will or the strength of the negotiating parties, the microphone in the mouthpiece that functions inadvertently as a tool of espionage, or transmitting the noise made by the vaporized telephone when the atomic bomb is dropped - all these technical disruptions, strategies, and (catastrophic) events are a constant reference to the material basis of the dedicated line between Washington and Moscow. Amongst the fictional and poetological aspects of the 'red telephone' is the fact that there is no attempt to camouflage its technical operations; on the contrary, instances of disruption are actively disclosed. This is the condition of possibility of the negotiations and at no point is it concealed that the technical basis of the discussions is highly unstable. The crisis-laden storyline thus acquires additional drama and an arena is opened up in which the likelihood of rectifying disruptions is rather low.

This constellation of technical media is supplemented by human actors whose rhetorical strategies and emotional outbursts further enrich the fictional dimension of the 'red telephone.' Thus, the functions of the body politic seem to be reversed and to have taken on new roles as a result of the crisis-ridden state of emergency. This is confirmed by the President's request at the beginning of the discussions to use only one interpreter, so as not to waste precious time on intricacies. Although not equipped with the necessary credentials, Buck empowers himself to play the role of ambassador by modifying the words of his superiors in order to de-escalate the situation. It may be due to this role reversal that the leaders at each end of the telephone line place such emphasis on their sovereignty as decision makers. Thus, Buck notices wrangling going on in the background in the Soviet operations center, following which Khrushchev feels compelled to assert his authority with the statement "I will make my own decisions" (Burdick and Wheeler 1999: 195). The American President also occasionally has to assert his identity as commander: "I have already given that order" (Burdick and Wheeler 1999: 194), he says into the 'red telephone,' affirming that he has ordered the shooting down of the American bombers.

In addition to this threat of dispersal on the level of command, the boundary between human and technical actors becomes permeable. The telephone line ap- 
pears to mock the President and to burst into macabre laughter when he relates his plan for the destruction of New York, prompting the narrator to conjecture on the presence of a soul in the technical system. The 'red telephone' thus proves to be an affect-laden technical apparatus (dispositif), a locus that rules out neutrality, where emotions are generated and exchanged.

And finally, in the process of interpreting, the question of message versus noise arises repeatedly, and which in the first instance is a question concerning channel noise in a communicational apparatus. In his mathematical information theory, Claude Shannon points out that a disruption in the communication channel is to be viewed as a message source on par with a message transmitter (Shannon and Weaver 1971: 3-8; Schüttpelz 2003: 16-17). If the signals from the message source are strong enough to be distinguished from the signal noise, the message can be decoded by a receiver. This is relevant in this instance, since Khrushchev's subdued as well as his decidedly strident, apocalyptic remarks are audible. The same is also true for "static interference" of human origin, however. Buck has to interpret the linguistic signs and at the same time decide whether the disruptive background noises at the Soviet end of the line are relevant messages (Luhmann 1990). The signal-to-noise ratio (Kittler 2013, for a reprint of this article see the "archive" in this volume) is therefore a problem on both the technical and the physiological level, and requires of Buck a feat of translation that goes well beyond mere translation from Russian into English. He cannot afford to wait for the encrypted messages to come to an end, since that could mean nuclear war, but after a phase of listening to what has been said he has to intervene, translate, and interpret in order to prevent the situation from escalating. ${ }^{3}$ During the preliminary briefing, the President stipulates that Buck should provide a translation that is "literally perfect," that it should convey “every emphasis I intend” (Burdick and Wheeler 1999: 129), but, in addition to serving as an extension of the body politic, simultaneous interpreting is also ultimately about listening in to Khrushchev's distinctly audible emotions and deciding how to interpret them.

As it is presented and takes shape in Fail-Safe, several discursive lines traverse the 'red telephone.' It is a medium that, far from attempting to conceal its susceptibility to disruption, actually foregrounds it. First of all, it is the locus of dramatic actions that raise questions regarding the sovereign ruler who communicates by telephone, encompassing not only specific constellations of personnel but also involving specific technical actors. The President's dis-

3 For the distinction between the activities of a doctor and an ambassadorial vice-consul read Foucault (Foucault 2001b: 559). 
course is equally dependent on his interpreter and the media technology that transforms sound into signals and mixes it with the noise and static of the communication channels. This also shows that knowledge of game theory, of military strategies, and mathematical information theory is embedded in the technical apparatus (dispositif) as such, thus linking it with scientific discourses of the time. The 'red telephone' is thus marked as an object of knowledge that can provide insight into a Cold War culture in which science and fiction have an equal impact.

\section{4}

Sidney Hook, Professor of Philosophy at New York University, was outraged. He vented his annoyance in the slim volume The Fail-Safe Fallacy, in which he endeavors to refute central facets of Burdick's and Wheeler's bestseller. His criticism mainly targets three aspects. First, he accuses the authors of misleadingly representing the American defense system, pointing out that there are security measures in place to deal with human failure as well as technical malfunctions. He thus finds it scandalous that Fail-Safe creates the impression that a nuclear war triggered by a technical defect is not only possible but unavoidable (Hook 1963a: 15). Human failures are more likely in this respect but could not lead to war, he maintains, because a single person acting alone never has access to nuclear weapons. In addition, the military personnel in question are screened for mental balance and subjected to intelligence tests carried out by machines (!) (Hook 1963a: 15-16).

Hook's second criticism is that the government's civilian experts in Fail-Safe are, as he sees it, cast in entirely the wrong light. Representatives of the Rand Corporation, such as Herman Kahn (who made it possible to utilize mathematical models such as the Nash equilibrium in the development of political strategies [Pias 2009]), and is represented in the novel by the fictional character Groteschele, are presented as sadistic, cold, calculating scientists who actually hankered for a nuclear war in order to be able to test their hypotheses. According to Hook, it was precisely the members of the think tanks who, thanks to their deliberations, were the ones who reduced the risk of accidental nuclear war (Hook 1963a: 19-23). Lastly, the New York philosopher is irritated by what he sees as the idealization of Khrushchev, who according to Hook is presented as “a philosopher pledged to reasonable compromise” (Hook 1963a: 24). The authors are accused of failing to understand both Khrushchev and the underlying political system; making the Communist "sound like a noble Roman senator" (Hook 1963a: 26), as Hook puts it, is absolutely beyond the pale. Hook's critique 
is of particular interest at those points where the question arises concerning the influence the novel could have on its readers.

There was a time when the themes of science fiction in novel and cinema were pure fantasies. Today a new genre has developed that prides itself on its concern with important and grim truth underlying the fictional detail. This pretension exacts a correspondingly great intellectual and moral responsibility to avoid fomenting hysteria. Intelligent fear may be a preface to appropriate action, but hysterical fear blinds one to alternatives. It would be commonly admitted that it is cruel to write a piece of science fiction or produce a film that, by distorting the facts, scares people witless about the incidence of some dread disease, thus making them gullible and receptive to fraudulent claims of cure. It is far worse to exaggerate the risks involved in the defense of freedom to a degree that dwarfs, in the minds of readers and viewers, the much greater and more immediate danger confronting a free and peaceful world. This is the great offense of the authors of Fail-Safe (Hook 1963a: 32).

Hook's main worry revolves around the possibility that the readers of Fail-Safe could find the plot of the novel credible. He fears that a work of science fiction could be utilized politically (Hook entitled a shorter review of the novel "The Politics of Science Fiction" [Hook 1963b: 82-88]) and jeopardize the security of the United States by conjuring up an overstated danger. "The authors," write Burdick and Wheeler in their preface, "have not had access to classified information but have taken some liberties with what has been declassified." But the entanglements of fact and fiction do not end there:

Thus the element in our story which seems most fictional - the story's central problem and its solution - is in fact the most real part. [...] The accident may not occur in the way we describe but the laws of probability assure us that ultimately it will occur. (Burdick and Wheeler 1999: 7-8)

This compositional procedure is the main target of Hook's critique: Burdick and Wheeler composed the story so skillfully, drawing on technical details and technical knowledge, that citizens might be thrown into a state of panic that could be channeled into political pressure, which in turn could lead to disarmament and thus a weakening of America's defense capability. In Hook's view, science fiction as exemplified by Fail-Safe thus becomes a danger to national security.

Some twenty years later, Jacques Derrida also described the relationship between an imaginary nuclear war, that is, between the "fabulous textuality" that deals with nuclear war, and the "reality of the nuclear age" (Derrida 2007: 394) that Western society was and is living through. This reality: 
is constructed by a fable, on the basis of an event that has never happened [...]. [It is] an invention because it depends upon new technical mechanisms, to be sure, but an invention also because it does not exist and especially because, at whatever point it should come into existence, it would be a grand premiere appearance. (Derrida 2007: 394)

For Derrida nuclear war is "fabulous" to the extent that it only arises and exists in the imagination - in texts, in myths, in rhetorical figures, in images or in scientific calculations. While the atomic bombs dropped on Hiroshima and Nagasaki put an end to the classical, conventional form of war, they did not trigger a nuclear war. The imaginary nuclear war has an effect on technical developments, on diplomatic and military strategies, on policy decisions, as well as cultural and civilizational formations. The fear of a fictitious event propels an insane arms race (Derrida 2007: 394-395). In his critique of Fail-Safe, Hook is dealing with just one constituent of the comprehensive textuality that characterized the Cold War era, and he is less concerned about the arms race than about the spread of hysteria in society, which could weaken public acceptance of the system of military deterrence. Fictions - on this point, Hook and Derrida are in agreement - can fabricate facts.

\section{5}

The 'red telephone' is one component of these Cold War fictions that left their mark on everyday reality. Conceived as a direct telephone link between Moscow and Washington, it made its way from literature and film into everyday culture and 'melded' with the hotline that was set up in 1963. The 'red telephone' thus finds its place at the interface between fact and fiction. For, on the one hand, it is a literary and filmic invention that adds drama to critical moments in storylines, and charges them with emotion. In addition to Fail-Safe, one should mention in this regard Peter George's novel, Red Alert, published in 1958, which assigns a central role to the 'red telephone.' Also pertinent are Sidney Lumet's film version of Fail-Safe and Stanley Kubrick's Dr. Strangelove, the former a political thriller, the latter a satire based on George's novel. On the other hand, an actual teletype link was indeed set up between Moscow and Washington, precisely in order to avoid the emotions that in discussions via telephone could lead to an escalation of the situation. A considered decision was made to dispense with a telephone connection so as to be able to examine an incoming message carefully, and to discuss and compose a precise answer. Walt Rostow, National Security Advisor to the American government at the time, highlighted this in an internal memorandum after the hotline was first 
used during the Six-Day War in 1967, closing with the words: "a message in writing is better than one spoken" (Rostow 1967: Doc 13). ${ }^{4}$ The hotline is a temporizing device that allows one to buy time in a crisis.

In 1931, the psycho-technician Franziska Baumgarten wrote a brief and fascinating article entitled "Psychology of Telephoning." She came to the conclusion that telephoning is both destructive and constructive. On the one hand, it can have a damaging effect on relationships: since one's counterpart is not visually present, telephoning encourages "a lack of emotional restraint." One can let oneself go, present oneself as more intrepid than one is, ignore facts or even tell untruths; in this regard, the telephone is a medium of escalation. On the other hand, the lack of visual interaction - and thus non-verbal communication - can be an advantage, conducive to de-escalation: it can make for an objectivity that can be helpful when talking to people:

who are insufferable when dealing with them in person [...]. The telephone not only provides us with a technical means of human communication but also makes it possible at a given moment to block out what we find objectionable about a person or persons and to maintain dispassionate relationships with those who are useful to us but otherwise disagreeable. (Baumgarten 1989 [1931]: 188-189)

This tension between escalation and de-escalation is a key circumstance that shapes the hybrid object 'red telephone' and defines its dramatic aspect. It is actively involved in a double crisis: first, there is the level of the political crisis that threatens to end in disaster, and where the 'red telephone' offers the last chance for a solution to be found. If the negotiations via the 'red telephone' should fail, then war appears inevitable, since there is no other diplomatic channel - whether telephonic or telegraphic - that stands above this privileged connection. Moreover, the telephone itself is marked by technical and linguistic disruptions, and is thus implicated in minor crisis situations, consequently redoubling the intensity of the crisis-laden events proper. It is this that constitutes the hybridity of the apparatus, of the dispositif: stories that, as a disruptive incident unfolds, are able to furnish us with knowledge of the respective operational chains and the conduct of the actors involved, stories which then progressively 'attach' themselves to the object 'telephone' and fashion it into the legendary apparatus that made its way into Western popular culture - and which then, after the Cold War, lapsed into increasing obscurity.

4 My research at the LBJ Library was made possible by a travel grant from the Fritz Thyssen Foundation. 


\section{Works Cited}

Aiken, F. B (1959) “Abraham '59 - A Nuclear Fantasy," Dissent 6, 18-24.

Baumgarten, Franziska (1989 [1931]) "Psychologie des Telephonierens," in Telefon und

Gesellschaft, vol. 1: Beiträge zu einer Soziologie der Telefonkommunikation, ed.

Forschungsgruppe Telekommunikation (Berlin: Volker Spiess), 187-196.

Berridge, G. R. (2005) Diplomacy. Theory and Practice (New York: Houndmills).

Burdick, Eugene and Harvey Wheeler (1999) Fail-Safe (Hopewell: Ecco Press).

Derrida, Jacques (1979) Of Grammatology, trans. Gayatri Spivak (Baltimore; London: The Johns Hopkins University Press).

Derrida, Jacques (2005) “The Word Processor," in Paper Machine, trans. Rachel Bowlby (Stanford: Stanford University Press).

Derrida, Jacques (2007) “No Apocalypse, Not Now: Full Speed Ahead, Seven Missiles, Seven Missives," in Psyche: Inventions of the Other, vol. 1, ed. Peggy Kamuf and Elizabeth Rottenberg, trans. Catherine Porter and Philip Lewis (Stanford: Stanford University Press), 387-410.

Dixit, Avinash and Barry J. Nalebuff (1991) Thinking Strategically: The Competitive Edge in Business, Politics and Everyday Life (New York; London: Norton).

Foucault, Michel (2001a) "Le jeu de Michel Foucault," in Dits et écrits, vol. 3, ed. Daniel Defert and François Ewald (Paris: Gallimard), 298-328.

Foucault, Michel (2001b) “Message ou Bruit?” in Dits et écrits, vol. 1, 1954-1969, ed. Daniel Defert and François Ewald (Paris: Gallimard), 557-560.

Hodges, Andrew (2012) Alan Turing: The Enigma (London: Vintage Books, Random House). Hook, Sidney (1963a) The Fail-Safe Fallacy (New York: Stein and Day).

Hook, Sidney (1963b) "The Politics of Science Fiction," Encounter 20 (May), 82-88.

Kittler, Friedrich (2013) "Signal-Rausch-Abstand," in Die Wahrheit der technischen Welt, ed. Hans Ulrich Gumbrecht (Berlin: Suhrkamp), 214-231.

Latour, Bruno (1993) We Have Never Been Modern, trans. Catherine Porter (Cambridge, Mass.: Harvard University Press).

Legendre, Pierre (2001) De la société comme texte: Linéaments d'une anthropologie dogmatique (Paris: Fayard).

Luhmann, Niklas (1990) "The Improbability of Communication," in Essays on Self-Reference (New York: Columbia University Press), 86-98.

McLuhan, Marshall (2001) "The Gadget Lover: Narcissus as Narcosis," in Understanding Media (London; New York: Routledge), 45-52.

N.N. (1959) “And Among New Contributors," Dissent 6, 24.

Nanz, Tobias (2014) “Das 'Rote Telefon'. Ein hybrides Objekt des Kalten Krieges,” Zeitschrift für Literaturwissenschaft und Linguistik 44.173, 135-148.

Pias, Claus (2009) "One-Man Think Tank. Herman Kahn, oder wie man das Undenkbare denkt," Zeitschrift für Ideengeschichte 3, 5-16.

Rostow, Walt (1967) Lyndon B. Johnson Library and Museum, NSF Subject File 6, Communications III, Doc. 13.

Ruddick, Nicolas (2012) “Adapting the Absurd Apocalypse: Eugene Burdick's and Harvey Wheeler's Fail-Safe and its Cinematic Progeny," in Future Wars. The Anticipations and the Fears, ed. David Seed (Liverpool: Liverpool University Press), 161-179.

Saussure, Ferdinand de (2011) Course in General Linguistics, trans. Wade Baskin (New York: Columbia University Press). 
Serres, Michel (1982) The Parasite, trans. Lawrence R. Schehr (Baltimore; London: Johns Hopkins University Press).

Schmitt, Carl (2008) Gespräch über die Macht und den Zugang zum Machthaber (Stuttgart: Klett-Cotta).

Schüttpelz, Erhard (2003) "Frage nach der Frage, auf die das Medium eine Antwort ist," in Signale der Störung, ed. Albert Kümmel and Erhard Schüttpelz (München: Wilhelm Fink), 15-29.

Shannon, Claude E. and Warren Weaver (1971) The Mathematical Theory of Communication (Urbana: University of Illinois Press), 3-8.

Vogl, Joseph (1999) “Einleitung," in Poetologien des Wissens, ed. idem (München: Wilhelm Fink), 7-16.

Vogl, Joseph (2007) “Becoming-Media: Galileo’s Telescope,” Grey Room 29 (Fall), 14-25. 
